\title{
NEUTRAL FRACTION OF THE OLEORESIN OF PINUS SILVESTRIS
}

II. Dehydroabietinol Acetate

E. N. Shmidt and V. A. Pentegova

Khimiya Prirodnykh Soedinenii, Vol. 5, No. 3, p. 187, 1969

We have previously [1] reported the isolated from the neutral high-boiling fraction of the oleoresin of Pinus silvestris L. (Scotch pine) of eight diterpene compounds. Continuing a study of the oleoresin, we have chromatographed the neutral fraction on silica gel containing $12 \%$ of silver nitrate. Petroleum ether containing $12 \%$ of diethyl ether eluted a crystalline substance with $\operatorname{mp} 60-61^{\circ} \mathrm{C},[\alpha]_{\mathrm{D}}^{20}+62.2^{\circ}$.

Its IR spectrum had bands at $835 \mathrm{~cm}^{-1}, 1510 \mathrm{~cm}^{-1}$ (aromatic ring), and 1250 and $1740 \mathrm{~cm}^{-1}$ (ether linkage). The UV spectrum had two maxima at 267 and $275 \mathrm{~m} \mu(\log \varepsilon 2.6,2.7)$; mol. wt. 318 (mass spectrometry).

From its spectral characteristics and elementary composition, this substance, $\mathrm{C}_{22} \mathrm{H}_{32} \mathrm{O}_{2}$, must be similar to derivatives of dehydroabietic acid $[2,3]$. Consequently, it may be assumed that it is the acetate of dehydroabietinol, a diterpene alcohol obtained by the reduction of dehydroabietic acid [4]. Dehydroabietinol acetate has the structure I:

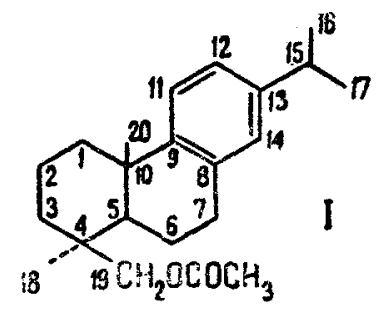

The nuclear magnetic resonance spectrum of the acetate fully confirms its structure. In the $\mathrm{NMR}$ spectrum (CCl $60 \mathrm{MHz})$ there are signals at $1.08 \mathrm{ppm}\left(\mathrm{C}_{10}-\mathrm{CH}_{3}\right) ; 1.13$ and $1.18 \mathrm{ppm}\left[\mathrm{C}_{4}-\mathrm{CH}_{3} ; \mathrm{C}_{15}-\left(\mathrm{CH}_{3}\right)_{2} ; \mathrm{J}=5 \mathrm{~Hz}\right] ; 1.81 \mathrm{ppm}$ $\left(\mathrm{CO}-\mathrm{CH}_{3}\right)$; and $3.55 \mathrm{ppm}\left(\mathrm{CH}_{2} \mathrm{OAc}\right)$.

In the weak-field region there are signals at $6.81 \mathrm{ppm}(1 \mathrm{H})$ and $6.91 \mathrm{ppm}(2 \mathrm{H} ; \mathrm{AB}, \mathrm{J}=7.5 \mathrm{~Hz})$ which shows the presence of a $1,2,4$-trisubstituted aromatic ring in the acetate.

A broadened singlet at $3.55 \mathrm{ppm}$ may be assigned to an equatorial $\mathrm{CH}_{2} \mathrm{OAc}$ group at $\mathrm{C}_{4}$. The possibility of the determination of the conformation of the side chains by the NMR method for diterpene compounds has been shown previously $[5,6]$.

Thus, the substance that we isolated is dehydroabietinol acetate and this is the first time that it has been obtained as a native product from the oleoresin of the Scotch pine.

The oleoresin of Pinus silvestris L. differs from the oleoresin of other Siberian conifers by the presence of aromatic diterpenes (dehydroabietinal [1], dehydroabietinol acetate), which may probably serve as an additional indication in the taxonomy of the subgenus Diploxylon.

\section{REFERENCES}

1. E. N. Shmidt and V. A. Pentegova, Izv. SO AN SSSR, no. 4, 144, 1968.

2. L. Fieser and W. P. Campbell, J. Amer. Chem. Soc., 60, 159, 1938.

3. E. E. Fleck and S. Palkin, J. Amer. Chem. Soc., 61, 247, 1939.

4. L. F. Fieser and W. P. Campbell, J. Amer. Chem. Soc. , 61, 2528, 1939.

5. A. Gaudemer, J. Polonsky, and E. Wenkert, Bull. Chim. Soc., France, 407, 1964.

6. C. R. Narayanan, N. R. Bhadane, Tetrah. Let., 1565, 1968. 